\title{
Mersin İli Mısır Üretim Alanlarında İstilacı Bir Zararlı: Chilo partellus (Swinhoe, 1885) (Lepidoptera: Crambidae)
}

\author{
Sevcan ÖZTEMIZ1 ${ }^{- \text {(D) }}$, Vahdettin AKMEŞE2 ${ }^{2}$ (D) \\ ${ }^{1}$ Düzce Üniversitesi Ziraat ve Doğa Bilimleri Fakültesi, Bitki Koruma Bölümü, 81620, Konuralp- Düzce, ${ }^{2}$ Biyolojik Mücadele Araştırma \\ Enstitüsü Müdürlüğ̈̈, 01321,Yüreğir, Adana, \\ \:sevcanoztemiz@gmail.com
}

\section{ÖZET}

İstilac1 tür, Chilo partellus (Swinhoe, 1885) (Lepidoptera: Crambidae)'un Tarsus/Mersin ili mısır üretim alanlarında varlığı bu çalışma ile 2016 yılında tespit edilmiştir. Bu tür 2014 yılında Türkiye'de ilk kez görülmesine rağmen, bugüne kadar Mersin ilinde tespit edilmemiştir. Zararlı Asya'nın yerli türü olup, Afrika'da yayılış göstermiştir. C. partellus çabuk kolonize olduğu ve zarar yaptığı her yerde, geniş coğrafi alanlara hızla yayılmıştır. Sıcaklık, nem ve konukçu bitkilerin bolluğu gibi uygun koşullarda oldukça zararlı olan istilacı tür, Türkiye'de mısırın ana zararlıları olan yerli türler, Mısır Koçankurdu, Sesamia nonagrioides Lefebvre (Lepidoptera: Noctuidae) ve Misırkurdu, Ostrinia nubilalis (Hübner) (Lepidoptera: Crambidae) ile rekabet ederek bunların yerini alabilecek kapasitededir. Bu nedenle, zararlının daha fazla yayılması önlenmeli ve mücadele önlemleri mümkün olduğunca çabuk alınmalıdır.
DOI:10.18016/ksudobil.343299

\author{
Makale Tarihçesi \\ Received : 17.01.2017 \\ Accepted : 12.04.2017
}

Anahtar Kelimeler
Chilo partellus,
istilacı tür,
misır,
Mersin

Araştırma Makalesi

\section{An Invasive Pest in Maize of Mersin: Chilo partellus (Swinhoe, 1885) (Lepidoptera: Crambidae)}

\section{ABSTRACT}

The presence of the invasive species, Chilo partellus (Swinhoe, 1885) (Lepidoptera: Crambidae) in corn production areas of Tarsus/Mersin province was determined in 2016 with this study. To date, the pest was not detected in the province of Mersin, albeit it was seen for the first time in 2014 in Turkey. The spotted stemborer is native to Asia and now widespread in Africa. Chilo partellus has rapidly spread over a wide range of geographical areas where it has colonized and made infestations. This pest can be highly invasive in favorable conditions such as warm temperatures, relative humidity and an abundance of host plants, and is able to compete and replace with the main maize pests and other indigenous stemborer species such as the Mediterranean corn stalk borer, Sesamia nonagrioides Lefebvre (Lepidoptera: Noctuidae) and the European corn borer, Ostrinia nubilalis (Hübner) (Lepidoptera: Crambidae), in Turkey. Therefore, control measures should be taken as soon as possible to prevent further spread of the pest.

\section{Article History \\ Geliş : 17.01.2017 \\ Kabul : 12.04.2017}

\author{
Keywords \\ Chilo partellus, \\ invasive, \\ maize, \\ Mersin
}

\section{Research Article}

To Cite : Öztemiz S, Akmeşe V,. 2018. Mersin İli Mısır Üretim Alanlarında İstilacı Bir Zararlı: Chilo partellus (Swinhoe, 1885) (Lepidoptera: Crambidae). KSÜ Tarım ve Doğa Derg 21(1):489-491, DOI:10.18016/ksudobil.343299.

\section{GİRIŞ}

Türkiye'de üretim miktarı bakımından buğday ve arpadan sonra üçüncü sırada yer alan mısır, insan ve hayvan beslenmesinde önemli bir ürün olmasının yanı sıra, endüstride geniş kullanım payına sahiptir. Ülkemizde tane ve silajlık mısır ekim alanı 1.111.293,2 hektar olup, 6.400.000 ton tanelik ve 19.684.599 ton silajlık mısır üretilmektedir (Anonim, 2015). Türkiye mısır üretiminin yaklaşık \%4'ü Mersin ilinde üretilmektedir (Anonim, 2015). Ülkemiz mısır üretim alanlarında verim kaybına neden olan ana zararlılar Mısır Koçankurdu, Sesamia nonagrioides Lef. (Lepidoptera: Noctuidae) ve Misırkurdu, Ostrinia nubilalis Hbn. (Lepidoptera: Pyralidae)'tir (Öztemiz ve ark., 2011). Her iki ana zararlı bitkinin kök bölgesi hariç tüm organlarında zarar yapmaktadır (Kamala ve ark., 2012). Özellikle ikinci ürün mısırlarda yüksek düzeyde popülasyon oluşturmakta ve mücadele 
yapılmadığı taktirde üründe önemli ekonomik kayılara neden olmaktadır (Tsitsipis, 1988; Sertkaya ve Kornoşor, 2000; Sertkaya ve ark., 2005). Misır kurtları ile rekabet edebilecek boyutta yeni bir istilacı tür, Chilo partellus (Swinhoe) (Lepidoptera: Crambidae), Ülkemize ilk defa 2014 yılında giriş yaparak Adana ve Hatay illerinde birinci ürün misır alanlarında kaydedilmiştir (Sertkaya ve ark., 2014). Bir başka çalışmada istilacı türün Adana ve Hatay illerine ilave olarak Osmaniye'de bulunduğu, ancak Mersin ilinde tespit edilmediği rapor edilmiştir (Bayram ve Tonğa, 2016). Bu amaçla çalışma ele alınmış olup, zararlı türün ilk kez görüldüğü Doğu Akdeniz Bölgesi’nde yayılış gösterip göstermediğini saptamak amaciyla daha önce tespit edilemeyen Mersin ilinde varlığının belirlenmesi hedeflenmiştir. Zararlının üreme potansiyelinin yüksek, yayılış alanının geniş olması ve bulunduğu bölgedeki mevcut zararlılar ile rekabete girmesi nedeniyle ülkemiz için ciddi bir tehdit oluşturduğu öngörülmektedir.

\section{MATERYAL ve METOT}

Çalışma 2016 yılında, Mersin ili ikinci ürün mısır üretim alanlarında yürütülmüştür. Periyodik olmayan arazi çıkışları ile haziran-eylül aylarında örneklemeler yapılmıştır. Mısır kurtları ile bulaşık bitkiler gözle kontrol yöntemi ile incelenmiş ve bulaşık bitki materyalinden toplanan zararlının ergin öncesi biyolojik dönemleri Düzce Üniversitesi Ziraat ve Doğa Bilimleri Fakültesi Entomoloji laboratuvarına getirilerek kültüre alınmıştır. Zararlı ile bulaşık bitki materyali ile birlikte alınan örnekler $25 \pm 1 \circ \mathrm{C}$ sicaklık ve $\% 65 \pm 10$ orantılı neme ayarlanmış üretim odasında kültüre alınmıştır (Öztemiz ve Kornoşor, 2004; Öztemiz ve ark., 2011). Laboratuvarda plastik kavanozlara konularak kültüre alınan larva ve pupalardan Misırkurdu ve Misır Koçankurdu'ndan farklı olduğu şüphelenilen örnekler ayrı plastik kültür kaplarına alınmıştır. Larvalara günlük besin olarak taze mısır sap ve koçanları verilmiştir. Kültürde larva gelişmesini tamamlayarak pupa olanlar ayrı pupa kültür kaplarına aktarılmıştır. Yaklaşık bir hafta sonra pupalardan ergin elde edilmiştir. Erginler teşhise hazır hale getirilerek Atay (2006)'ya göre teşhis edilmiş ve örnekler daha önce toplanan ve koleksiyonda mevcut örnekler ile karşılaştırılarak doğruluğu teyit edilmiştir.

\section{BULGULAR, TARTISMA ve SONUC}

Çalışmada C. partellus (Swinhoe)'un ikinci ürün misırda yaprak, sap ve tepe püskülünde beslenen larvaları ilk kez 23.VIII.2016 tarihinde Tarsus/Mersin'de (3655'3.58" N 34 53 '33.97" E, 23 m) kayıt edilmiştir. Arazi çıkışlarında mısırda ana zararlılardan $S$. nonagrioides Lef. ve $O$. nubilalis Hbn.'in de bitkilerde zararı ve ergin öncesi biyolojik dönemleri tespit edilmiş, fakat C. partellus'un daha yoğun olduğu görülmüştür. Mısır bitkisinde $C$. partellus'un ilk dönem larvalarının merkezi yapraklarda ve özellikle orta damarda beslenme zararı, gövde de oyuk, tepe püsküllerinden saplara girdiği ve aşağı doğru kurumaların olduğu belirlenmiştir. Mısır alanları için büyük risk teşkil eden yeni zararlı, C. partellus 1930'lu ylllardan önce Hindistan'da, 1932 yılında Malavi'de, 1952 yılında Tanzanya'da kaydedilmiştir (Overholt ve ark., 1994). Zararlının, Afrika'nın sıcak ve düşük rakımlı olan doğu ve güney bölgelerinde yayılış alanını genişleterek $1600 \mathrm{~m}$ yüksekliğe kadar olan bölgelerde popülasyon oluşturduğu rapor edilmiştir (Kfir, 1997). Güney Afrika'da C. partellus popülasyonunun özellikle tane sorgumda hızla artarak iki yıl içinde \%90'a ulaştığ 1 ve hâkim tür olan, Busseola fusca F. (Lepidoptera: Noctuidae)'nın yerini aldığı bildirilmiştir (Kfir, 1997). Türkiye'deki varlığı ise ilk kez 2014 yılında Doğu Akdeniz Bölgesi Adana, Hatay ve Osmaniye illerinde tespit edilmiştir (Sertkaya ve ark., 2014; Bayram ve Tonğa, 2016). Bu çalışma ile zararlının Doğu Akdeniz Bölgesi yayılış alanına Mersin ili de ilave edilerek $C$. partellus ile bulaşık il sayısı dörde ulaşmıştır. Mısır ve sorgum ekiliş alanlarında önemli ürün kayıplarına neden olan $C$. partellus erginlerinin misir bitkisinin 610 yapraklı dönemini yumurta bırakmak için tercih ettiği ve yumurtalarını genellikle yaprağın alt yüzüne paket halinde bıraktığ tespit edilmiştir. Bir dişinin ortalama 100-166 yumurta biraktığı, yumurtaların 710 günde açıldığı, larva gelişmesini iklim koşullarına bağlı olarak 28-35 günde tamamlayarak sap içerisinde pupa olduğu ve pupa gelişmesini 8-10 günde tamamladiğı rapor edilmiştir (Ofomata ve ark., 2000). Ayrıca, C. partellus sicaklığın sifirın altında olduğu yüksek yerlerde kışı diyapozda saplarda veya toprakta larva halinde geçirmektedir (Kfir, 1997). Görüldüğü gibi ülkemizin özellikle güney bölgesi, zararlının gelişmesi için uygun iklim koşulları ve konukçu bitkilere sahip olması bakımından önemli bir risk potansiyeline sahiptir. İklim değişikliğinin zararlılar üzerindeki etkisini değerlendirmek amacıyla yapılan bir araştırmada $C$. partellus'un yayılış alanının daha yüksek rakımlara, yüksek tropiklere, nemli geçiş bölgelerine ve zararlının henüz kaydının yapılmadığı mısır yetiştiriciliği yapılan bölgelere doğru ilerleyeceği bildirilmiştir (Le Ru ve Khadioli, 2015). Ayrıca, C. partellus'un neden olduğu ürün kaybının \%24-75 arasında değiştiği rapor edilmiştir (Kumar ve Mihm, 1995; Kumar, 2002; Khan, 1983). Pakistan'da yapılan başka bir çalışmada ise zararlıdan kaynaklanan ürün kaybının \%10-50 arasında olduğu (Farid ve ark., 2007) bildirilmiştir.

Ülkemizde son üç yıldır varlığı bilinen istilacı türün daha fazla yayılış alanı bulamaması için bir an önce zararlı ile ilgili temel araştırmaların yanı sıra uygun alternatif mücadele yöntemlerinin araştırılması gerekmektedir. 


\section{KAYNAKLAR}

Anonim 2015. Türkiye İstatistik Kurumu, Konularına göre istatistikler, Bitkisel Üretim istatistikleri, Ankara. http://www.tuik.gov.tr, (Erişim tarihi: 17.09.2016).

Atay E 2006. The identity of Parapoynx affinialis (Guenée, 1854) (Lepidoptera, Crambidae, Nymphulinae)' in Turkey. Turkish Journal of Entomology, $3: 76-81$.

Bayram A, Tonğa A 2016. First Report of Chilo partellus in Turkey, A New Invasive Maize Pest for Europe. Journal of Applied Entomology, 140 : 236240.

Farid A, Khan MIN, Khan A, Khattak SUK, Alamzeb Sattar A 2007. Study on Maize stem borer, Chilo partellus (Swin.) in Peshawar Valley, Pakistan Journal of Zoology, 9(2): 127-131.

Kamala V, Sharma CH, Raho MD, Varaprasad SK, Bramer JP, Chandra S 2012. Interactions of Spotted stem borer Chilo partellus With Wild Relatives of Sorghum. Plant Breeding, 131: 511521.

Khan BM 1983. Studies on the Biology and Control of Maize stem borer in Peshawar. Zoological Bulletin, 1: 51-56.

Kumar H, Mihm JA 1995. Antibiosis and Tolerance to Fall armyworm, Spodoptera frugiperda (J. E. Smith), Southwestern corn borer, Diatraea grandiosella Dyar and sugarcane borer, Diatraea saccharalis Fabricius in Selected Maize Hybrids and Varieties. Maydica, 40:245-51.

Kumar H 2002. Resistance in Maize to Larger grain borer, Prosphanus truncates (Horn) (Coleoptera: Bostrichidae). Journal of Stored Products Research, 38: 267-280.

Kfir R 1997. Competitive Displacement of Busseola fusca (Lepidoptera: Noctuidae) by Chilo partellus (Lepidoptera: Pyralidae). Annals of Entomological Society of America, 90: 619-624.

Le Ru B, Khadioli N 2015. Adaptation to Pest Risks Under Future Climates in Africa, Maize pestsSpotted stemborer, Chilo partellus (Swinhoe). Technical Report, January 2015, 27-28p.

Ofomata VC, Overholt WA, Lux SA, Van Huis A, Egwuatu RI 2000. Comparative Studies on the
Fecundity, Egg Survival, Larval Feeding and Development of Chilo partellus (Swinhoe) and Chilo orichalcociliellus Strand (Lepidoptera: Crambidae) on Five grasses. Annals of Entomological Society of America, 93: 492-499.

Overholt WA, Ogedah K, Lammers PM 1994. Distribution and Sampling of Chilo partellus (Swinhoe) (Lepidoptera:Pyralidae) in Maize and Sorghum at the Kenya Coast. Bulletin of Entomological Research, 84: 367-378.

Öztemiz S, Kornoşor S 2004. Trichogramma evanescens Westwood (Hymenoptera, Trichogrammatidae)'in Ostrinia nubilalis Hübner (Lepidoptera, Pyralidae) Yumurtalarında Farklı Sıcaklık ve Nem Koşullarında Biyolojisi. Çukurova Üniversitesi Ziraat Fakültesi Dergisi, 19 (3) : 73-82.

Öztemiz S, Güllü M, Göven MA, Fidan H, Aksoy E, Bülbül ZF, Yılmaz E, Gözüaçık C, Akyol H, Caner ÖK, Duran H, Velioğlu S, Erdoğan C 2011. Misır Entegre Mücadele Teknik Talimatı. (Ed: Atlamaz A, Gökçe AY). T.C. Gıda Tarım ve Hayvancılık Bakanlığı, Tarımsal Araştırmalar ve Politikalar Genel Müdürlüğü, Bitki Sağlığı Araştırmaları Daire Başkanlığı. Ankara.128 s.

Sertkaya E, Kornoşor S 2000. Çukurova'da Mısır koçankurdu, Sesamia nonagrioides Lef. (Lepidoptera: Noctuidae)'in Doğal Düşmanları. Türkiye 4. Entomoloji Kongresi, 12-15 Eylül, Aydın, 339348.

Sertkaya E, Bayram A, Kornoşor S 2005. Balcalı (Adana)'da Mısır koçankurdu, Sesamia nonagrioides Lef. (Lep.:Noctuidae)'in Kışlayan Dölünün Larva ve Pupa Parazitoitleri ve Ichneumon sarcitorius L. (Hymenoptera: Ichneumonidae)'un Doğal Parazitleme Oranı. Mustafa Kemal Üniversitesi Ziraat Fakültesi Dergisi, 10 (1-2): 31-36.

Sertkaya E, Akmeşe V, Atay E 2014. Türkiye'de Misırda Yeni Bir Zararll, Chilo partellus (Swinhoe) (Lepidoptera: Crambidae). Türkiye Entomoloji. Bülteni, 4 (3): 197-200.

Tsitsipis JA 1988. The Corn stalk borer, Sesamia nonagrioides: Forecasting, Crop-Loss Assesment and Pest Management. Integrated Crop Protection in Cereals. Balkema, Rotherdam, Brookfield, 171177. 